\title{
Role of biochemical factors in the pathogenesis of keratoconus
}

\author{
Katarzyna A. Wojcik ${ }^{1}$ Janusz Blasiak ${ }^{凶}$, Jerzy Szaflik² and Jacek P. Szaflik² \\ 1Faculty of Biology and Environmental Sciences, Department of Molecular Genetics, University of Lodz, Łódź, Poland; ${ }^{2}$ Department of Ophthal- \\ mology, Medical University of Warsaw and Samodzielny Publiczny Kliniczny Szpital Okulistyczny, Warszawa, Poland
}

Keratoconus $(\mathrm{KC})$ is a corneal disease associated with structural abnormalities in the corneal epithelium, Bowman's layer and stroma and altered concentration of tear components. KC corneas show a different pattern of collagen lamellae than their normal counterparts. Also, a reduction of several collagen types in $\mathrm{KC}$ epithelium and stroma was observed. Altered expression and/or activity of lysyl oxidase, a critical enzyme of the biogenesis of connective tissue detected in KC corneas, may weaken covalent bonds between collagen and elastin fibrils, what may lead to biomechanical deterioration of the cornea. Increased activity of matrix metalloproteinases observed in KC may induce the degradation of the extracellular matrix causing damage to the cornea. Oxidative and nitrative stress play an important role in KC pathogenesis and KC corneas are characterized by the disturbed lipid peroxidation and nitric oxide pathways. Malfunctioning of these pathways may lead to accumulation of their toxic by-products inducing several detrimental effects, along with apoptosis of the corneal cells, which may result from the loss of $\beta$-actin or increased levels of cytokines, including interleukin- 1 and -6 . Change in the expression of genes associated with wound healing, including the nerve growth factor and the visual system homeobox 1, may contribute to increased susceptibility of KC corneas to injury. Consequently, biochemical changes may play an important role in KC pathophysiology and, therefore, can be considered in prevention, diagnosis, prognosis and in the therapy of this disease as well.

Key words: keratoconus, cornea, collagen, proteinases, proinflammatory markers, antioxidants

Received: 09 October, 2013; revised: 14 December, 2013; accepted: 21 February, 2014; available on-line: 18 March, 2014

\section{INTRODUCTION}

Keratoconus $(\mathrm{KC})$ is a bilateral and usually asymmetrical ectatic eye disease, in which the cornea assumes a conical shape. Keratoconus typically occurs in teens and progress until the third or fourth decade of life. The signs and symptoms of $\mathrm{KC}$ vary depending on stage and severity of the disease. In the initial stage, the disorder has no symptoms, therefore the diagnosis is difficult and only specific tests, such as corneal topography, allow to identify the disease. With the disease progression, patients with $\mathrm{KC}$ decrease quality of vision resulting from development of irregular astigmatism and myopia (Rabinowitz, 1998; Romero-Jiménez et al., 2010; Ahmadi Hosseini et al., 2013).
Keratoconus is characterized by a central or paracentral stromal thinning, resulting in alteration in the corneal curvature (Rabinowitz, 1998). A decrease in keratocyte density, a reduction in the number of lamellae and a degradation of fibroblasts in $\mathrm{KC}$ corneal stroma were reported (Romero-Jiménez et al., 2010). In addition, changes in the gross organization of the lamellae, and an uneven distribution of collagen fibrillar mass, especially around the apex of the cone, were observed in KC corneas (Meek et al., 2005).

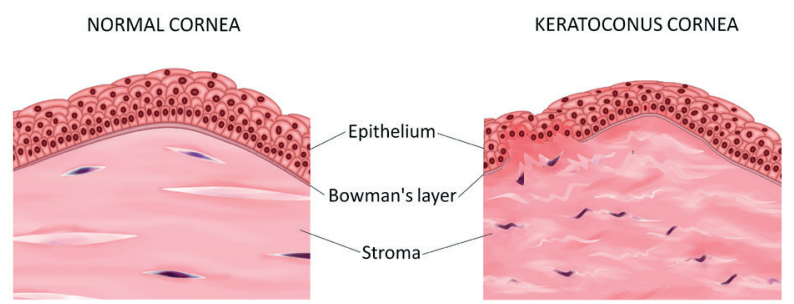

Figure 1. Epithelium and Bowman's layer from normal and keratoconus corneas, showing structural changes, including central epithelial thinning and breaks in Bowman membrane, typical for keratoconus.

Moreover, structural abnormalities were revealed in the central part of Bowman's layer, a condensed layer of collagen, in KC-affected corneas. Sharply edged defects and interruptions in Bowman's layer resulting from collagen bundles separation can be observed in this disease (Fig. 1). Breaks in Bowman's layer are usually filled with collagen derived from the stroma (Rabinowitz, 1998). Keratoconus is characterized by a thinning of the central part of epithelium. A positive correlation was reported between the occurrence of breaks in Bowman's layer and the extent of such thinning (Sherwin \& Brookes, 2004). Keratoconus corneas show also a line partially or completely surrounding the cone, called Fleischer's ring (Romero-Jiménez et al., 2010). Other KC typical signs are ruptures and folds in posterior limiting membrane, (Descemet's membrane), that may lead to acute stromal edema, sudden vision loss and pain (Sherwin \& Brookes,

e-mail: janusz.blasiak@biol.uni.lodz.pl

Abbreviations: ALDH3, aldehyde dehydrogenase Class 3; ECM, extracellular matrix; HGF, hepatocyte growth factor; IL-1, interleukin-1; IL-6, interleukin-6; INPPL1, inositol polyphosphate phosphatase-like 1; KC, keratoconus; LOX, lysyl oxidase; MMP, matrix metalloproteinase; MMP-2, matrix metalloproteinase-2; NGF, nerve growth factor; PON1, paraoxonase 1; SNP, single nucleotide polymorphism; SOD1, superoxide dismutase 1; SOD3, extracellular superoxide dismutase; TIMP, tissue inhibitor of matrix metalloproteinases; TrkANGFR, NGF-receptor TrkA; VEGF, vascular endothelial growth factor; VSX1, visual system homeobox 1 


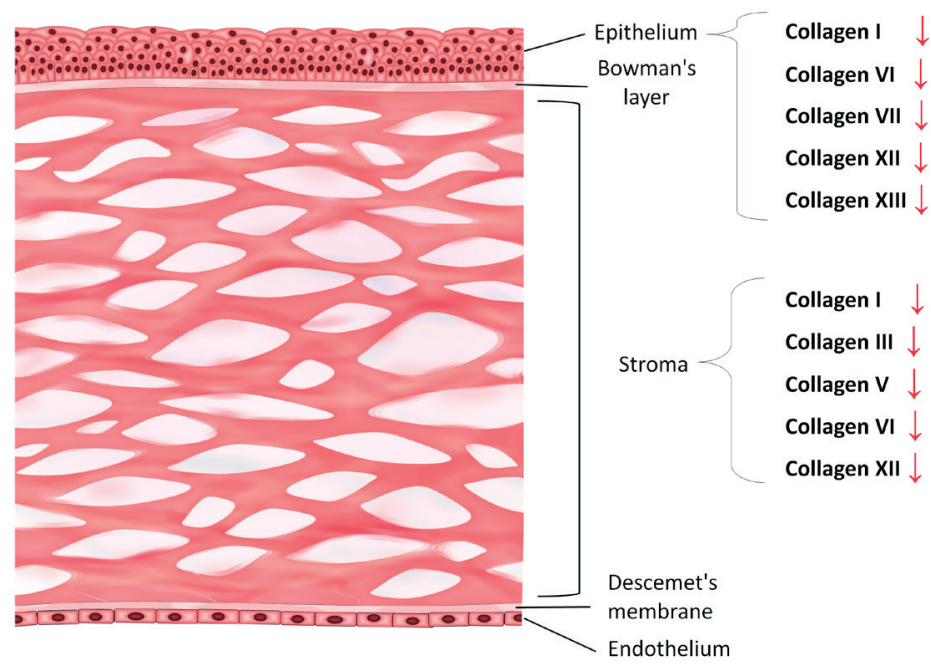

Figure 2. Reduction of collagens in layers of the keratoconus corneas. Epithelium exhibits reduction in type I, VI, VII, XII and XIII collagens, while corneal stroma has decreased levels of type I, III, V, XII and VI collagens.

2004). Descemet's membrane is a thin cellular layer located between the corneal stroma and endothelium, which is rarely affected in $\mathrm{KC}$, except for pleomorphism, intracellular dark structures and elongation of corneal cells (Sherwin \& Brookes, 2004). Keratoconus is manifested by the occurrence of fine vertical lines in the deep stroma and Descemet's membrane, termed Vogt's striae (Rabinowitz, 1998). The disease is associated with superficial and deep corneal opacities that can occur in different stages of this disorder (Sherwin \& Brookes, 2004).

Keratoconus is likely a multifactorial disease and several processes, also of biochemical nature, can contribute to its development (Kenney \& Brown, 2003; Chaerkady et al., 2013). However, biochemical aspects of $\mathrm{KC}$ are not known completely. The corneal thinning in $\mathrm{KC}$ is likely caused by the degradation of the extracellular matrix (ECM) components and loss of keratocytes, but the source of these changes has not been recognized yet.

\section{COLLAGEN AND BETA-ACTIN}

Results of several studies suggest that the corneal thinning, typical for KC, may be underlined by a decreased amount of total collagen, the main corneal protein, and an alteration in ECM structure in KC corneas (Quantock \& Young, 2008; Stabuc-Silih et al., 2009).

In the stroma, collagen is composed of heterotypic fibrils containing mainly collagen type $\mathrm{I}$ and $\mathrm{V}$ and smaller amounts of type VI, XII, XIII, XIV and XXIV (Michelacci, 2003; Meek, 2009). Type XII collagen was detected in the stroma in the area near to Bowman's and Descemet's membranes, whereas type XIII was found in the posterior stroma (Meek, 2009). Type XVIII collagen is localized in the corneal epithelium and epithelial basement membrane (Michelacci, 2003). The arrangement of the collagen lamellae in $\mathrm{KC}$ corneas differs from that in normal corneas (Radner et al., 1998). Collagen fibrils in $\mathrm{KC}$ do not show delimited collagen lamellae, but form uniform layers and the interlacing between adjacent collagen layers are decreased or even absent. A disruption in the collagen organization in $\mathrm{KC}$ may result from disturbances in the process of formation of corneal extracellular components, resulting in their damage or structural changes in collagen fibers and collagen lamellae
(Rabinowitz, 1998). Keratoconus epithelium displayed a reduction of collagen types VII and XII (COL7A1, COL12A1) as well as all three chains of type VI (COL6A1, COL6A2 and COL6A3), whereas KC stroma showed a decreased content of collagen type I, III, V, XII and VI (Cheng et al., 2001; Chaerkady et al., 2013) (Fig. 2). Results of immunological studies suggest an altered expression of collagen type XIII in KC (Määttä et al., 2006). In addition, a decrease in the content of proteoglycans, including decorin, lumican, biglycan and keratocan was observed in $\mathrm{KC}$. These proteoglycans interact with fibrillar collagens, making them biomechanically strong, refractive and transparent (Chaerkady et al., 2013). Furthermore, a decreased concentration of transforming growth factor beta (TGF- $\beta$ ) was observed in KC. TGF- $\beta$ can interact with several collagen types and proteoglycans. It is also involved in cell junction, facilitating contact between cells and ECM (Runager et al., 2011; Chaerkady et al., 2013). Collagen plays a crucial role in the maintenance of corneal shape and its transparency, therefore disturbance in collagen structure or arrangement may lead to a mechanical weakening of the cornea and vision deterioration (Chaerkady et al., 2013).

Collagen cross-linking is a first-line treatment of $\mathrm{KC}$ patients, involving the formation of bonds between collagen molecules, fibres and microfibrils, which strengthen the cornea (Viswanathan \& Males, 2012). In its basic form, collagen cross-linking involves activation of riboflavin by UV-A radiation and forming of new bonds between adjoining collagen strands in the corneal stroma. General success of this procedure confirms the importance of collagen content and distribution in the structural relationship in the cornea.

Several genes encoding collagen were considered as candidate genes in KC (Stabuc-Silih et al., 2009; Karolak et al., 2011, Nielsen et al., 2013). The analysis of $C O L A A 3$ and $C O L A A 4$ genes in a Slovenian population showed that P141L, D326Y and G859G single nucleotide polymorphisms (SNPs) in COL4A3, P482S, M1237V, V1516V and F1644F in COL $4 A 4$ had a different genotype distribution in $\mathrm{KC}$ patients and controls (Stabuc-Silih et al., 2009). Screening of mutations in CO$L 4 A 1$ and COL $4 A 2$ genes in 15 Ecuadorian families with $\mathrm{KC}$ revealed numerous alterations in both genes, but none of variants was associated with familial KC (Karolak et al., 2011). SNPs found near or within the COL $5 A 1$ gene, which encode a component of type V collagen at the 9q34.2-3 region, were associated with corneal thinning in $\mathrm{KC}$ ( $\mathrm{Li}$ et al., 2013). Genome-wide studies identified a $\mathrm{KC}$ locus in the chromosomal region $3 p 14-q 13$. This region contains $\alpha 1$ chain of type VIII collagen gene (COL $8 A 1)$. However, genetic analyses of COL $8 A 1$ and COL $8 A 2$ genes indicated no pathogenic mutations associated with KC (Aldave et al., 2007; Nielsen et al., 2013). A novel potential KC susceptibility region located at $2 \mathrm{q} 21.3$ was recently identified, suggesting the involvement of $\mathrm{RAB} 3 \mathrm{GAP1}$ gene, encoding Rab3 GTPase-activating protein subunit 1 (Li et al., 2012). Although several correlations between polymorphisms in collagen genes and $\mathrm{KC}$ were found, it seems that most abnormalities in corneal collagen structure observed in $\mathrm{KC}$ are not associated with variation in collagen genes and, therefore, probably other different genetic factors are involved in the degradation of ECM components. 
Biomechanical properties of the cornea depend largely on the corneal collagen cross-linking (Dudakova et al., 2012). Owing to the fact that lysyl oxidase (LOX), a critical enzyme in the biogenesis of connective tissue, catalyzes formation of bonds between collagen and elastin in ECM, LOX gene may be considered as a candidate for $\mathrm{KC}$ susceptibility. An increased LOX mRNA level observed in $\mathrm{KC}$ corneas compared to their age-matched controls confirms this assumption (Nielsen et al., 2013). However, a lower LOX activity in tissue culture medium with KC corneal fibroblasts and a decreased LOX activity in all corneal layers, particularly in the stromal matrix were observed (Dudakova et al., 2012). Analysis of SNPs in LOX gene showed an association between its variants and $\mathrm{KC}$ both in familial and sporadic cases (Bykhovskaya et al., 2012). Change in LOX expression or activity of its product in corneal tissue may cause a decrease in cross-linking of collagen fibers, resulting in a biomechanical weakening of the cornea and contribute to $\mathrm{KC}$ development.

It was hypothesized that an increased apoptosis of keratocytes observed in $\mathrm{KC}$ corneal stroma might be caused by the loss of $\beta$-actin, a non-muscle cytoskeletal protein involved in cell structure, integrity and motility (Karakozova et al., 2006). The KC stroma exhibited a significant reduction of the $\beta$-actin gene expression and a complete loss of this protein in $\mathrm{KC}$ corneas was observed (Joseph et al., 2012; Srivastava et al., 2006). Loss of $\beta$-actin may induce destabilization of the cytoskeleton of keratocytes and their apoptosis leading to a decrease in number of $\mathrm{KC}$ corneal cells, but exact effect of changes in $\beta$-actin levels is unclear and requires further studies (Joseph et al., 2012).

\section{PROTEOLYTIC ENZYMES AND THEIR INHIBITORS}

Degradation of collagen and increased cell death in $\mathrm{KC}$ corneas may result from an increased level of proteolytic enzymes, inluding cathepsin-B, -G, -V/L2 and lysosomal enzymes (Fig. 3) (Chwa et al., 2008, Arnal et al., 2011).

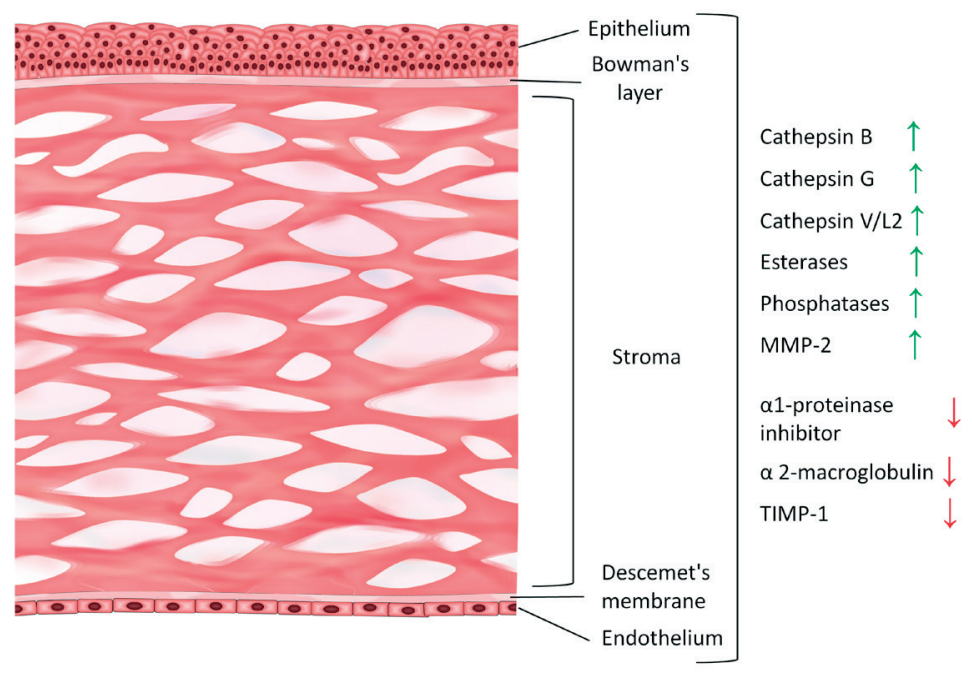

Figure 3. Changes in levels and/or activities of degradative enzymes and their inhibitors in the keratoconus corneas.

Increased levels of cathepsin-B, $-G$, and $-V / L 2$, acid esterases, acid phosphatases, and decrease in a1-protease inhibitor, a2-macroglobulin and tissue inhibitors of matrix metalloproteinase (TIMP-1) can be observed in KC. In addition, matrix metalloproteinase-2 (MMP-2) activity is increased in KC corneas.
Cathepsins are proteases present in lysosomes that can activate caspases, the main apoptotic executors (Roberg et al., 1999). Enhanced protease activity may contribute to ECM degradation and corneal thinning (Sherwin et al., 2002, Kenney et al., 2005). Moreover, an increased cathepsin activity may destabilize mitochondria and stimulate the formation of mitochondrial reactive oxygen species (ROS), contributing to oxidative stress (Zhao et al., 2003, Kenney et al., 2005). Increased levels of acid esterases, acid phosphatases, and acid lipases were also found in KC corneas (Critchfield et al., 1988). Moreover, a decreased level of two major proteinase inhibitors in the plasma $\alpha 1$-protease inhibitor and $\alpha 2$-macroglobulin was observed in $\mathrm{KC}$ epithelium and stroma (Sawaguchi et al., 1990, 1994). The $\alpha 1$-proteinase inhibitor blocks the activity of trypsin, chymotrypsin, elastase and plasmin, whereas $\alpha 2$-macroglobulin inhibits trypsin, chymotrypsin, papain, collagenase, elastase, thrombin, plasmin and kallikrein (Kenney \& Brown, 2003).

Matrix metalloproteinase-2 (MMP-2) is the main corneal matrix metalloproteinase and its increased activity was observed in keratoconic corneas (Kao et al., 1982, Brown et al., 1993). However, more recent studies found no alteration in MMP-2 levels in KC (Zhou et al., 1998, Kenney et al., 2005). An imbalance between matrix metalloproteinases and their tissue inhibitors (TIMPs) in KC may influence corneal proteinase activity and may contribute to corneal thinning. A decreased level of TIMP-1 mRNA in KC corneas was observed (Kenney et al., 2005, Kenney \& Brown 2003). Keratocyte cultures from KC corneas had higher levels of MMP-2/TIMP-1 compared to cells of normal corneas (Kenney et al., 1994, 2005). TIMP-1 has also anti-apoptotic properties, so keratocyte apoptosis in KC corneas may be associated with abnormal level of this inhibitor (Matthews et al., 2007). Moreover, MMP-14, the membrane-type metalloproteinase that activates MMP-2, was reported to increase in $\mathrm{KC}$ corneas (Kenney \& Brown 2003). A sequence analysis of MMP-2, MMP-9 and TIMP-1 genes found no mutation associated with KC (Brown et al., 2004, Joseph et al., 2011). Although increased level of cellular proteases and reduction of their inhibitors might cause the destruction of ECM in KC corneas, the roles of MMP2 and TIMP-1 in KC are still controversial and require further studies.

\section{CYTOKINES AND GROWTH FACTORS}

Keratoconus corneas show a loss of keratocytes in the anterior corneal stroma following epithelial abrasion (Wilson et al., 1996). Reduction of these cells is likely caused by an increased apoptotic cell death in KC corneas (Wilson et al., 1992). An increased number of interleukin-1 (IL-1) receptors in KC keratocytes compared to their normal counterparts was demonstrated (Bereau et al., 1993). IL-1 is produced by both corneal epithelial and endothelial cells (Wilson et al., 1996). Results of an in vitro studies suggest that IL-1 induces keratocyte death and negative chemotaxis as well as upregulates hepatocyte and keratinocyte growth factor in corneal stromal fibroblasts (Wise et al., 1994, Wilson et al., 1996). IL-1 can also regulate the expression of metalloproteinases, collagenase and complement factors (Wilson et al., 1996, Girard et al., 


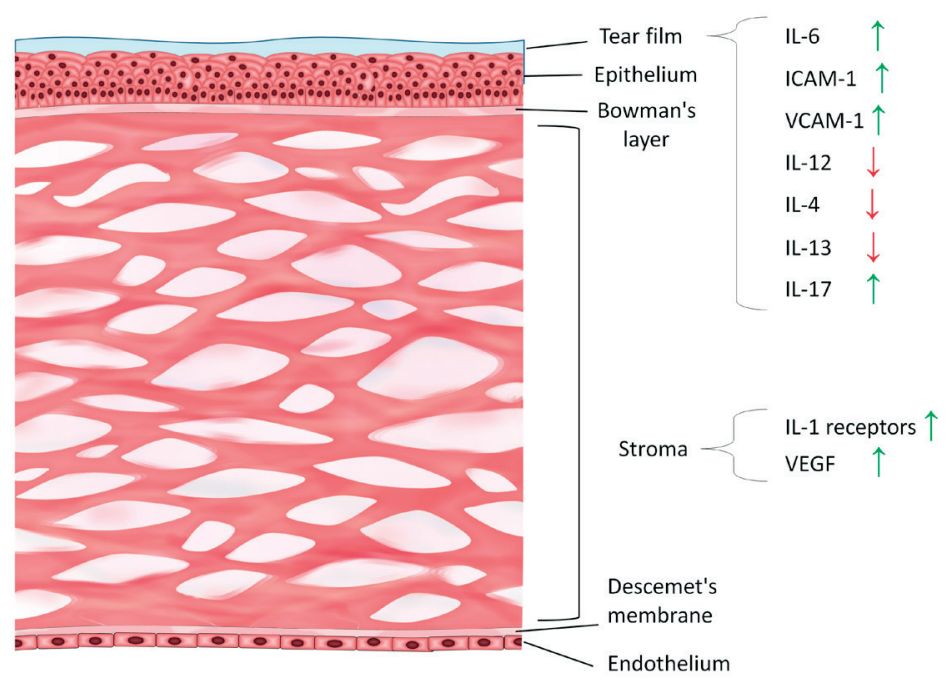

Figure 4. Altered levels of cytokines and growth factors in keratoconus. Keratoconus corneas have increased number of interleukin-1 (IL-1) receptors and enhanced level of vascular endothelial growth factor (VEGF), while keratoconic tear films show decreased levels of interleukin-12 (IL-12), interleukin-4 (IL4), and interleukin-13 (IL-13), and increased levels of interleukin-6 (IL-6), ICAM-1, VCAM-1 and interleukin-17 (IL-17).

1991). Increased expression of IL-1 receptor in keratoconic corneal fibroblasts may trigger off a higher sensitivity of cells to IL-1 released from the epithelium and endothelium (Wilson et al., 1996). Increased sensitivity of keratocytes to IL-1 may lead to their reduction due to apoptosis and a gradual loss of stromal mass (Wilson et al., 1996). This hypothesis would explain an association between $\mathrm{KC}$ and eye rubbing, contact lens wear, and atopy. Chronic contact lenses wearing may cause an increased release of IL-1 in epithelium, facilitating a slow, progressive loss of corneal fibroblasts (RomeroJiménez et al., 2010). Eye rubbing and atopy may induce similar effect in KC cornea (Wilson et al., 1996). Genetic analysis showed an association between SNPs in the promoter region of the interleukin-1 beta (IL1B) gene, a SNP in intron 6 of the IL-1 alpha (IL1A) and an increased susceptibility to $\mathrm{KC}$ in Korean patients (Kim et al., (2008)). Moreover, a significant association between SNPs in the promoter region of the IL1B gene and $\mathrm{KC}$ in Japanese patients was shown (Mikami et al., 2013). SNPs in IL-1 receptor antagonist (IL1RN) were observed more frequently in familial $\mathrm{KC}$ than in normal population (Nowak et al., 2013). These results support hypothesis that IL-1 may play an important role in $\mathrm{KC}$ development.

The tear film in $\mathrm{KC}$ shows also increased levels of proinflammatory markers, including interleukin-6 (IL-6), ICAM-1 and VCAM-1 (Fig. 4). Eye rubbing in normal subjects leads to increased levels of IL-6 in tear fluids (Balasubramanian et al., 2013). It was suggested that cytokines produced in the cornea or conjunctiva were accumulated and transferred by tears. Inflammatory molecules may induce apoptosis in keratocytes that is the major mode of cell death in KC corneas (Lema et al., 2009). Persistent eye rubbing might induce increased levels and activity of corneal cytokines, which contribute to the development or progression of the disease (Balasubramanian et al., 2013). However, cytokine level in the serum displayed no differences between $\mathrm{KC}$ patients and controls, supporting the hypothesis on the lack of association between $\mathrm{KC}$ and major systemic inflammation (Jun et al., 2011).
A decreased level of IL-12, IL-4, and IL13 was observed in keratoconic tear films (Jun et al., (2011)). In contrary, an increase in IL-17 level was detected in some KC cases. IL-4 is involved in the regulation of cell proliferation and tissue homeostasis (Nelms et al., 1999). It was found that IL-4 and IL13 were involved in the synthesis of collagen type I and III in dermal fibroblasts and intrahepatic cells (Aoudjehane et al., 2008). Reduction of IL-4 in the corneal environment may lead to a decreased survival of stromal keratocytes, induction of oxidative stress and reduced level of collagens observed in $\mathrm{KC}$ corneas (Jun et al., 2011). Several results suggest that IL-17 is associated with the production of proteases associated with tissue degradation, so elevated level of IL-17 may induce tissue damage in KC (Cortez et al., 2007; Qiu et al., 2009; Jun et al., 2011).

Cytokines play an important role in the regulation of many processes and an imbalance between pro-inflammatory and antiinflammatory cytokines may induce cascades of intracellular signaling leading to changes in several cellular processes. Aberrations in levels of some interleukins observed in $\mathrm{KC}$ may stimulate an increased production of metalloproteinases, and other proteinases as well as enhance apoptosis in keratocytes, resulting in weakening of the corneal stroma.

Vascular endothelial growth factor (VEGF), which plays an important role in the pathogenesis of several diseases of the eye including age-related macular degeneration, was reported to overexpress in $\mathrm{KC}$ corneas and bullous keratophaty, but its expression decreased in diabetic corneas (Saghizadeh 2001). If even the increased level of VEGF in $\mathrm{KC}$ results from its involvement in the pathogenesis of the disease, this involvement may not be associated with basic VEGF functions, vasculogenesis and angiogenesis, due to the structure of the cornea supporting its transparent character.

As mentioned above, a reduced expression of transforming growth factor beta (TGF- $\beta$ ) was observed in KC (Saghizadeh et al., 2001). A further work showed a potential usefulness of TGF- $\beta$ as a marker in severe $\mathrm{KC}$ and an importance of TGF- $\beta$ signaling in the pathophysiology of KC (Engler et al., 2011). Some contradictory results were obtained in the analysis of variability in TGF- $\beta$ genes in different populations - an association was reported in a Chinese subpopulation (Guan et al., 2012), whereas a lack of it was reported in the American one (Udar et al., 2004). Transforming growth factor beta 2 can be found in the aqueous humor, where it plays an important role in the immunological response in the anterior chamber of the eye, and also its increased level was reported in KC eyes (Maier et al., 2007). This can have a prognostic significance for $\mathrm{KC}$ patients undergoing penetrating keratoplasty.

\section{ANTIOXIDANTS}

Results of some studies indicated aberrant structure and function of antioxidant enzymes in $\mathrm{KC}$ corneas. Screening of the superoxide dismutase 1 (SOD1) gene in $15 \mathrm{KC}$ families revealed a 7-base deletion in the intron 2 in two KC families (Udar et al., 2006). Moreover, mRNA analysis indicated the presence of two additional 
transcript splice variants encoding proteins lacking the active site of the SOD1 enzyme. Superoxide dismutase is an important antioxidant enzyme that metabolizes superoxide radicals to molecular oxygen and hydrogen peroxide (Valko et al., 2006). There are three major types of this enzyme: SOD1 located in the cytoplasm, SOD2 in the mitochondria, and extracellular SOD3 (McCord \& Fridovich, 1969; Weisiger \& Fridovich, 1973; Marklund, 1982). A deletion in SOD1 gene may influence structure of the enzyme and was reported to decrease its activity in familial KC corneas (Udar, 2006, 2009). However, later research did not detect changes in SOD1 gene in both sporadic and familiar KC cases (Gajecka et al., 2009; De Bonis et al., 2011). Results of other studies indicated a decreased level of SOD3 activity in KC corneas (Behndig et al., 2001). Despite the decrease in SOD3 activity in $\mathrm{KC}$, the level of SOD3 mRNA was unaltered in this disease (Kenney et al., 2005). It was shown that the synthesis of SOD3 is reduced by IL-1 in cultured $\mathrm{KC}$ stromal cells in contrast to normal keratocytes that showed an increase in SOD3 synthesis (Olofsson et al., 2007). Therefore, the release of IL- $1 \alpha$ in the KC corneas may lead to a reduction of SOD3 synthesis in the corneal stroma, which in turn contributes to an increased oxidative stress.

A reduced level of aldehyde dehydrogenase Class 3 (ALDH3) was detected in KC epithelial extracts (Gondhowiardjo et al., 1993). This enzyme plays an important role in the neutralization of reactive aldehydes of the lipid peroxidation pathway (Bhuyan \& Bhuyan, 1978; Sophos et al., 2001). However, there was no change in ALDH3A1 RNA levels in KC corneas compared to normal corneas (Kenney et al., 2005). The lack of correlation between mRNA levels of SOD3 and ALDH3A1 and their activities may result from post-translational modifications, changes in enzyme turnover rate or genetic polymorphisms.

A decreased paraoxonase 1 (PON1) activity was observed in $\mathrm{KC}$ patients compared to non-keratoconic subjects in a Malaysian population (Poh et al., 2012). PON1 displays antioxidative properties that protect both low-

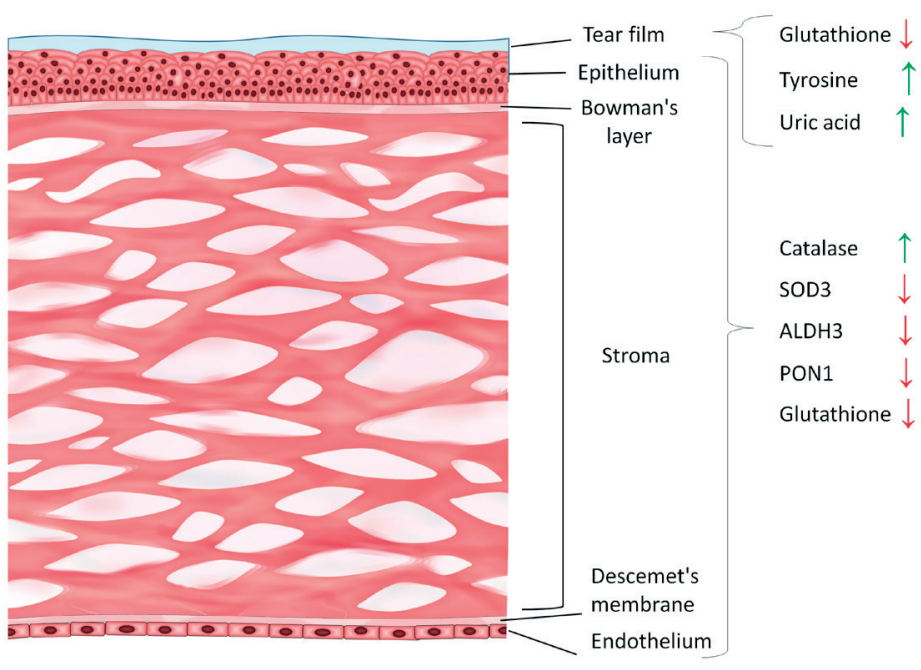

Figure 5. Change in levels and/or activities of antioxidants in keratoconus. Keratoconus corneas have decreased levels and/or activities of extracellular superoxide dismutase (SOD3), paraoxonase 1 (PON1), aldehyde dehydrogenase Class 3 (ALDH3) and glutathione, and increased levels of catalase. In addition, increased concentrations of tyrosine and uric acid along with a decrease in glutathione levels was observed in keratoconus tear film. and high-density lipoproteins against oxidation and reduce lipid peroxidation.

Keratoconus corneas were reported to have increased catalase mRNA levels, suggesting that they had elevated cincetrations of $\mathrm{H}_{2} \mathrm{O}_{2}$ (Kenney et al., 2005; Bhuyan \& Bhuyan, 1978; Valko et al., 2006). Altered antioxidant enzymes activities may result in elevated levels of superoxide radicals, hydrogen peroxide, hydroxyl radicals and other ROS, that react with cellular and extracellular compounds including proteins, nucleic acids, and membrane phospholipids (Valko et al., 2006).

Small molecular weight, non-enzymatic antioxidants, including reduced glutathione (GSH), ascorbic acid, cysteine, uric acid and tyrosine, also have a significant role in the regulation of cellular redox status and protection of cells against oxidative damage (Birben et al., (2012)). Keratoconus corneas displayed a decreased glutathione content and total antioxidant capacity (Arnal et al., 2011). Moreover, an increased concentration of tyrosine and uric and a decreased level of glutathione were observed in $\mathrm{KC}$ tear film, but the concentration of ascorbic acid did not differ from that observed in control tears (Saijyothi et al., 2012). Alternation in levels of GSH suggests an increased levels of ROS and altered redox status. Glutathione is involved in the neutralization of ROS and maintains some antioxidants, including vitamins $\mathrm{C}$ and $\mathrm{E}$, in their reduced forms (Gukasyan et al., 2007). Significant lowering of the glutathione and total antioxidant capacity in $\mathrm{KC}$ corneas and tears indicate increased oxidative stress in this tissue that may induce oxidative damage to corneal components.

Reduced level of antioxidants in the cornea may cause the accumulation of cytotoxic products resulting in alteration of various corneal proteins involved in several pathological processes in KC corneas (Fig. 5). Increased levels of reactive aldehydes can disrupt the membranes of lysosomes resulting in the release of their content. In addition, ROS can contribute to altered protein functions leading to a cascade of events, including apoptosis, collagen resorption, tissue degradation, and corneal thinning (Kenney \& Brown, 2003).

Changes in antioxidant status of keratoconus corneas support an important role of oxidative stress in the pathogenesis of this disease (Wojcik et al., 2013).

\section{CORNEAL WOUND HEALING}

It was suggested that $\mathrm{KC}$ corneas are more susceptible to injury due to disturbance in wound healing. A lack of NGF-receptor TrkA (TrkANGFR) expression and a significant decreased expression of nerve growth factor (NGF) and p75 neurotrophin receptor (p75NTR) was observed in KC (Lambiase et al., 2005). NGF is an important molecule involved in trophism and wound healing of the cornea. Moreover, NGF influences in vitro corneal epithelial-cell proliferation and differentiation and promotes impairment of corneal sensitive nerves. The absence of TrkANGFR expression may be associated with an increase in the Sp3 short isoform(s) and a lack of the Sp3 long isoform. Imbalance between the Sp transcription-factor isoforms may play a role in the controlling of NGF signaling leading to a progression of the disease. 
A positive correlation between mutations in the visual system homeobox 1 gene (VSX1) and $\mathrm{KC}$ occurrence was reported (Stabuc-Silih et al., 2010). VSX1 gene encodes a transcription factor, which is involved in craniofacial and ocular development (Semina et al., 2000). It was shown that mutations in VSX1 were associated with anomalous development of the corneal endothelium that may be involved KC pathogenesis. Moreover, a strong association between VSX1 expression and corneal wound healing was found (Barbaro et al., 2006). Variation in VSX1 gene may impact function of its protein and increase the susceptibility of KC corneas to injury (Dash et al., 2010). It seems that VSX1 may play a role in several pathways of $\mathrm{KC}$ pathogenesis and further studies are needed to clarify it (Abu-Amero et al., 2011).

The variability of regulatory RNAs may be important in $\mathrm{KC}$ pathogenesis as shown in the case of mutations in miR-184 gene in familial KC (Hughes et al., 2011). It is suggested that miR-184 plays a role in the repair of corneal injury through the regulation of the expression of the inositol polyphosphate phosphatase-like 1 gene (INPPL1). Deregulation of INPPL1 expression may increase susceptibility of corneal cells to apoptosis and this may underline the involvement of miR-184 in $\mathrm{KC}$ pathogenesis.

\section{OTHERS FACTORS}

As mentioned above, a correlation between SNPs located near the gene encoding a catalytic subunit of RAB3GAP and KC susceptibility was shown (Li et al., 2012). RAB3GAP activates the Rab3 GTPase that is involved in the regulation of calcium-mediated hormone and neurotransmitter exocytosis. Rab3 proteins are necessary for functioning and normal structural development of the eye. Alterations in the RAB3GAP may lead to a defect in the vesicular membrane transport. However, the precise explanation of how the loss of RAB3GAP function causes anomalies in the eye remains unknown ( $\mathrm{Li}$ et al., 2012; Wheeler et al., 2012).

An association between mutations in DOCK9 gene and familial KC was found (Burdon \& Vincent, 2013). DOCK9 (dedicator of cytokinesis 9) activates the cell cycle regulator, CDC42, belonging to the Rho family of GTPases, but its exact role in KC pathogenesis needs explanation.

An association between $\mathrm{KC}$ occurrence and SNPs in the promoter region of the hepatocyte growth factor (HGF) gene was reported (Burdon et al., 2011). Results of some studies detected a correlation between HGF and refractive errors, particularly with myopia and changes in HGF levels, may be linked with impairment of visual acuity in $\mathrm{KC}$. In addition, HGF gene promoter contains binding sites for the proinflammatory cytokine IL-6, thus it appears that the influence of HGF on $\mathrm{KC}$ may be associated with inflammatory pathways (Burdon \& Vincent, 2013; Burdon et al., 2011).

\section{CONCLUSIONS AND PERSPECTIVES}

Biochemical processes underlying the development of keratoconus seem to play an important role in its pathogenesis. Corneal thinning, which is a clinical hallmark of $\mathrm{KC}$, is associated with the destruction of ECM by increased activity of proteolytic enzymes, including metalloproteinases, and decreased level of their inhibitors. A concerted action of ECM-degrading enzymes and their regulators result in decreased levels of several collagen types and different pattern of collagen lamellae in $\mathrm{KC}$ epithelium and stroma. However, deregulation of metalloproteinases and their inhibitors as well as other proteinases, including cathepsins, in the $\mathrm{KC}$ cornea should be causatively associated with clinical signs of KC. Imbalance between oxidants and antioxidants, resulting in oxidative stress, a major KC pathogenesis factor, can be underlined by changes in biochemical properties of antioxidant enzymes, often resulted from mutations in their genes. Although we are far from complete understanding all biochemical processes in the cornea, it is clear that modulation of these processes can be important in $\mathrm{KC}$ pathogenesis. Therefore, these processes can be considered as diagnostic and prognostic indicators in $\mathrm{KC}$ and can be take into account as potential targets in $\mathrm{KC}$ therapy.

Biochemical factors are already considered to be important in $\mathrm{KC}$ diagnosis, that is supported by deposition of hemosiderin in Fleicher's ring, which appearance belongs to canonical criteria of the disease. This is an example of the contribution of biochemical factors to gross physical changes observed in $\mathrm{KC}$ by various imaging procedures, including keratometry, videocartography, the Orbscan II, the Pentacam and aberrometry. Several other biochemical factors are used to distinguish between normal and $\mathrm{KC}$-affected eyes, but they are not directly measured in diagnostic routine. Instead, the consequence of changes of biochemical features typical for $\mathrm{KC}$ eyes are visualized. Therefore, better understanding of mechanisms leading to changes visualized with current diagnostic apparatus may lead to the extension of the range of observed changes, and may contribute to work out technologies resulting in new diagnostic tools with a higher resolution and allowing for an earlier detecting of the disease presentation as well as its more accurate prognosis.

Biochemical factors involved in $\mathrm{KC}$ pathology and pathogenesis may be exploited to modify properties of KC corneas. Corneal collagen crosslinking with UV and riboflavin is the most significant example supporting this thesis. This procedure is considered as the only one, which may directed the normal pathway of $\mathrm{KC}$ into lessdevastating route. Although collagen-crosslinking was enthusiastically welcomed in ophthalmological society almost 20 years ago, there is still a lack of large population-based clinical trials on the effectiveness of this procedure (Vaziriani \& Basu, 2013). Therefore, further studies on the role of collagen in KC pathogenesis may lead to modifications of collagen-crosslinking procedure, resulting in its better clinical suitability and wider application. This, in turn, may provide more reliable clinical data, contributing to further modification of the procedure.

Although keratoconus was firstly documented in the middle of the 19th century, our knowledge on molecular mechanism underlying pathogenesis of the disease is limited. Biochemical changes in the cornea associated with the course of the disease may be important for KC diagnosis, prognosis and therapy, and thus should be studied to obtain further clinically-relevant information.

\section{Acknowledgements}

This study was supported by the grant N N402 591940 of Polish Ministry of Science and Higher Education.

\section{Conflict of interest statement}

The authors do not declare any conflict of interest. 


\section{REFERENCES}

Abu-Amero KK, Kalantan H, Al-Muammar AM (2011) Analysis of the $V S X 1$ gene in keratoconus patients from Saudi Arabia. Mol Vis 17: $667-672$.

Ahmadi Hosseini SM, Mohidin N, Abolbashari F, Mohd-Ali B, Santhirathelagan CT (2013) Corneal thickness and volume in subclinical and clinical keratoconus. Int Ophthalmol 33: 139-145.

Aldave AJ, Bourla N, Yellore VS, Rayner SA, Khan MA, Salem AK, Sonmez B (2007) Keratoconus is not associated with mutations in COL $8 A 1$ and COL $8 A 2$. Cornea 26: 963-965.

Aoudjehane L, Pissaia A Jr, Scatton O, Podevin P, Massault PP, Chouzenoux S, Soubrane O, Calmus Y, Conti F. (2008) Interleukin-4 induces the activation and collagen production of cultured human intrahepatic fibroblasts via the STAT-6 pathway. Lab Invest 88 : 973-985.

Arnal E, Peris-Martínez C, Menezo JL, Johnsen-Soriano S, Romero FJ (2011) Oxidative stress in keratoconus? Invest Ophthalmol Vis Sci 52: 8592-8597.

Balasubramanian SA, Pye DC, Willcox MD (2013) Effects of eye rubbing on the levels of protease, protease activity and cytokines in tears: relevance in keratoconus. Clin Exp Optom 96: 214-218.

Barbaro V, Di Iorio E, Ferrari S, Bisceglia L, Ruzza A, De Luca M, Pellegrini G (2006) Expression of VSX1 in human corneal keratocytes during differentiation into myofibroblasts in response to wound healing. Invest Ophthalmol Vis Sci 47: 5243-5250.

Behndig A, Karlsson K, Johansson BO, Brännström T, Marklund SL (2001) Superoxide dismutase isoenzymes in the normal and diseased human cornea. Invest Ophthalmol Vis Sci 42: 2293-2296.

Bereau J, Fabre EJ, Hecquet C, Pouliquen Y, Lorans G (1993) Modification of prostaglandin E2 and collagen synthesis in keratoconus fibroblasts associated with an increase of interleukin-1 alpha receptor number. CR Acad Sci III 316: 425-430.

Bhuyan KC, Bhuyan DK (1978) Superoxide dismutase of the eye: relative functions of superoxide dismutase and catalase in protecting the ocular lens from oxidative damage. Biochim Biophys Acta 542: 28-38.

Birben E, Sahiner UM, Sackesen C, Erzurum S, Kalayci O (2012) Oxidative stress and antioxidant defense. World Allergy Organ J 5 :9-19.

Brown D, Chwa MM, Opbroek A, Kenney MC (1993) Keratoconus corneas: increased gelatinolytic activity appears after modification of inhibitors. Curr Eye Res 12: 571-581.

Brown DJ, Lin B, Chwa M, Atilano SR, Kim DW, Kenney MC (2004) Elements of the nitric oxide pathway can degrade TIMP-1 and increase gelatinase activity. Mol Vis 10: 281-288.

Burdon KP Macgregor S, Bykhovskaya Y, Javadiyan S, Li X, Laurie KJ, Muszynska D, Lindsay R, Lechner J, Haritunians T, Henders AK, Dash D, Siscovick D, Anand S, Aldave A, Coster DJ, Szczotka-Flynn L, Mills RA, Iyengar SK, Taylor KD, Phillips T, Montgomery GW, Rotter JI, Hewitt AW, Sharma S, Rabinowitz YS, Willoughby C, Craig JE (2011) Association of polymorphisms in the hepatocyte growth factor gene promoter with keratoconus. Invest Ophthalmol Vis Sci 52: 8514-8519.

Burdon KP, Vincent AL (2013) Insights into keratoconus from a genetic perspective. Clin Exp Optom 96: 146-154.

Bykhovskaya Y, Li X, Epifantseva I, Haritunians T, Siscovick D, Aldave A, Szczotka-Flynn L, Iyengar SK, Taylor KD, Rotter JI, Rabinowitz YS (2012) Variation in the lysyl oxidase (LOX) gene is associated with keratoconus in family-based and case-control studies. Invest Ophthalmol Vis Sci 53: 4152-4157.

Chaerkady R, Shao H, Scott SG, Pandey A, Jun AS, Chakravarti S (2013) The keratoconus corneal proteome: Loss of epithelial integrity and stromal degeneration. J Proteomics 87: 122-131.

Cheng EL, Maruyama I, SundarRaj N, Sugar J, Feder RS, Yue BY (2001) Expression of type XII collagen and hemidesmosome-associated proteins in keratoconus corneas. Curr Eye Res 22: 333-340.

Chwa M, Atilano SR, Hertzog D, Zheng H, Langberg J, Kim DW, Kenney MC (2008) Hypersensitive response to oxidative stress in keratoconus corneal fibroblasts. Invest Ophthalmol Vis Sci 49: 43614369.

Cortez DM, Feldman MD, Mummidi S, Valente AJ, Steffensen B, Vincen (2007) IL-17 stimulates MMP-1 expression in primary human cardiac fibroblasts via p38 MAPK- and ERK1/2-dependent C/ EBP-beta, NF-kappaB, and AP-1 activation. Am J Physiol Heart Circ Physiol 293: H3356-3365.

Critchfield JW, Calandra AJ, Nesburn AB, Kenney MC (1988) Keratoconus: I. Biochemical studies. Exp Eye Res 46: 953-963.

Dash DP, George S, O'Prey D, Burns D, Nabili S, Donnelly U, Hughes AE, Silvestri G, Jackson J, Frazer D, Héon E, Willoughby CE (2010) Mutational screening of VSX1 in keratoconus patients from the European population. Eye (Lond) 24: 1085-1092.

De Bonis P, Laborante A, Pizzicoli C, Stallone R, Barbano R, Longo C, Mazzilli E, Zelante L, Bisceglia L (2011) Mutational screening of VSX1, SPARC, SOD1, LOX, and TIMP3 in keratoconus. Mol Vis 17: $2482-2494$.
Dudakova L, Liskova P, Trojek T, Palos M, Kalasova S, Jirsova K (2012) Changes in lysyl oxidase (LOX) distribution and its decreased activity in keratoconus corneas. Exp Eye Res 104: 74-81.

Engler C, Chakravarti S, Doyle J, Eberhart CG, Meng H, Stark WJ, Kelliher C, Jun AS (2011) Transforming growth factor- $\beta$ signaling pathway activation in Keratoconus. Am J Opbthalmol 151: 752-759.

Gajecka M, Radhakrishna U, Winters D, Nath SK, Rydzanicz M, Ratnamala U, Ewing $K$, Molinari A, Pitarque JA, Lee K, Leal SM, Bejjani BA (2009) Localization of a gene for keratoconus to a 5.6$\mathrm{Mb}$ interval on 13q32. Invest Ophthalmol Vis Sci 50: 1531-1539.

Girard MT, Matsubara M, Fini ME (1991)Transforming growth factor-beta and interleukin-1 modulate metalloproteinase expression by corneal stromal cells. Inves Ophthalmol Vis Sci 32: 2441-2454.

Gondhowiardjo TD, van Haeringen NJ, Völker-Dieben HJ, Beekhuis HW, Kok JH, van Rij G, Pels L, Kijlstra A (1993) Analysis of corneal aldehyde dehydrogenase patterns in pathologic corneas. Cornea 12: $146-154$.

Guan T, Liu C, Ma Z, Ding S (2012) The point mutation and polymorphism in keratoconus candidate gene TGFBI in Chinese population. Gene 503: 137-139.

Gukasyan HJ, Kim KJ, Lee VH, Kannan R (2007). Glutathione and its transporters in ocular surface defense. Ocul. Surf 5: 269-279

Hughes AE, Bradley DT, Campbell M, Lechner J, Dash DP, Simpson DA, Willoughby CE (2011) Mutation altering the miR-184 seed region causes familial keratoconus with cataract. Am J Hum Genet 89: 628-633.

Joseph R, Srivastava OP, Pfister RR (2011) Differential epithelial and stromal protein profiles in keratoconus and normal human corneas. Exp Eye Res 92: 282-298.

Joseph R, Srivastava OP, Pfister RR (2012) Downregulation of $\beta$-actin gene and human antigen $\mathrm{R}$ in human keratoconus. Invest Ophthalmol Vis Sci 53: 4032-4041.

Jun AS, Cope L, Speck C, Feng X, Lee S, Meng H, Hamad A, Chakravarti $S$ (2011) Subnormal cytokine profile in the tear fluid of keratoconus patients. PLos One 6: e16437.

Kao WWY, Vergnes JP, Ebert J, SundarRaj CV, Brown SI (1982) Increased collagenase and gelatinase activities in keratoconus. Biochem Biopbys Res Commun 107: 929-936.

Karakozova M, Kozak M, Wong CC, Bailey AO, Yates JR 3rd, Mogilner A, Zebroski H, Kashina A (2006) Arginylation of $\beta$-actin regulates actin cytoskeleton and cell motility. Science 313: 192-196.

Karolak JA, Kulinska K, Nowak DM, Pitarque JA, Molinari A, Rydzanicz M, Bejjani BA, Gajecka M (2011) Sequence variants in CO$L 4 A 1$ and COLAA2 genes in Ecuadorian families with keratoconus. Mol Vis 17: 827-843.

Kenney MC, Brown DJ (2003) The cascade hypothesis of keratoconus. Cont Lens Anterior Eye 26: 139-146.

Kenney MC, Chwa M, Atilano SR, Tran A, Carballo M, Saghizadeh M, Vasiliou V, Adachi W, Brown DJ (2005) Increased levels of catalase and cathepsin V/L2 but decreased TIMP-1 in keratoconus corneas: evidence that oxidative stress plays a role in this disorder. Invest Ophthalmol Vis Sci 46: 823-832.

Kenney MC, Chwa M, Opbroek AJ, Brown DJ (1994) Increased gelatinolytic activity in keratoconus keratocyte cultures. A correlation to an altered matrix metalloproteinase-2/tissue inhibitor of metalloproteinase ratio. Cornea 13: 114-124.

Kim SH, Mok JW, Kim HS, Joo CK (2008) Association of $-31 \mathrm{~T}>\mathrm{C}$ and $-511 \mathrm{C}>\mathrm{T}$ polymorphisms in the interleukin 1 beta (IL 1B) promoter in Korean keratoconus patients. Mol Vis 14: 2109-2116.

Lambiase A, Merlo D, Mollinari C, Bonini P, Rinaldi AM, D' Amato M, Micera A, Coassin M, Rama P, Bonini S, Garaci E (2005) Molecular basis for keratoconus: lack of TrkA expression and its transcriptional repression by Sp3. Proc Natl Acad Sci USA 102: 16795-16800.

Lema I, Sobrino T, Durán JA, Brea D, Díez-Feijoo E (2009) Subclinical keratoconus and inflammatory molecules from tears. $\mathrm{Br} \mathrm{J} \mathrm{Oph-}$ thalmol 93: 820-824.

Li X, Bykhovskaya Y, Canedo AL, Haritunians T, Siscovick D, Aldave AJ, Szczotka-Flynn L, Iyengar SK, Rotter JI, Taulor KD, Rabinowitz YS (2013) Genetic association of COL5A1 variants in keratoconus patients suggests a complex connection between corneal thinning and keratoconus. Invest Ophthalmol Vis Sci 54: 2696-2704.

Li X, Bykhovskaya Y, Haritunians T, Siscovick D, Aldave A, Szczotka-Flynn L, Iyengar SK, Rotter JI, Taylor KD, Rabinowitz YS (2012) A genome-wide association study identifies a potential novel gene locus for keratoconus, one of the commonest causes for corneal transplantation in developed countries. Hum Mol Genet 21: $421-429$

Määttä M, Väisänen T, Väisänen MR, Pihlajaniemi T, Tervo T (2006) Altered expression of type XIII collagen in keratoconus and scarred human cornea: Increased expression in scarred cornea is associated with myofibroblast transformation. Cornea 25: 448-453.

Marklund SL (1982) Human copper-containing superoxide dismutase of high molecular weight. Proc Natl Acad Sci USA 79: 7634-7638.

Matthews FJ, Cook SD, Majid MA, Dick AD, Smith VA (2007) Changes in the balance of the tissue inhibitor of matrix metallo- 
proteinases (TIMPs)-1 and -3 may promote keratocyte apoptosis in keratoconus. Exp Eye Res 84: 1125-1134.

McCord JM, Fridovich I (1969) Superoxide dismutase: an enzymic function for erythrocuprin (hemocuprein). Biol Chem 244: 60496055.

Meek KM (2009) Corneal collagen — its role in maintaining corneal shape and transparency. Biophysical Reviews 1: 83-93.

Meek KM, Tuft SJ, Huang Y, Gill PS, Hayes S, Newton RH, Bron AJ (2005) Changes in collagen orientation and distribution in keratoconus corneas. Invest Ophthalmol Vis Sci 46: 1948-1956.

Michelacci YM (2003) Collagens and proteoglycans of the corneal extracellular matrix. Braz J Med Biol Res 36: 1037-1946.

Mikami T, Meguro A, Teshigawara T, Takeuchi M, Uemoto R, Kawagoe T, Nomura E, Asukata Y, Ishioka M, Iwasaki M, Fukagawa K, Konomi K, Shimazaki J, Nishida T, Mizuki N (2013) Interleukin 1 beta promoter polymorphism is associated with keratoconus in a Japan population. Mol Vis 19: 845-851.

Nelms K, Keegan AD, Zamorano J, Ryan JJ, Paul WE (1999) The IL-4 receptor: signaling mechanisms and biologic functions. Annu Rev Immunol 17: 701-738.

Nielsen K, Hjortdal J, Pihlmann M, Corydon TJ (2013) Update on the keratoconus genetics. Acta Ophthalmol 91: 106-113.

Nowak DM, Karolak JA, Kubiak J, Gut M, Pitarque JA, Molinari A, Bejjani BA, Gajecka M (2013) Substitution at IL1RN and deletion at SLC4A11 segregating with phenotype in familial keratoconus. Invest Ophthalmol Vis Sci 54: 2207-2215.

Olofsson EM, Marklund SL, Pedrosa-Domellöf F, Behndig A (2007) Interleukin- $1 \alpha$ downregulates extracellular-superoxide dismutase in human corneal keratoconus stromal cells. Mol Vis 13: 1285-1290.

Poh R, Tan JA, Deva JP, Poo D, Yong Y, Arjunan S (2012) Paraoxonase 1 status in keratoconus: a preliminary study of activity and polymorphism. West Indian Med J 61: 569-573.

Qiu Z, Dillen C, Hu J, Verbeke H, Struyf S, Van Damme J, Opdenakker G (2009) Interleukin-17 regulates chemokine and gelatinase B expression in fibroblasts to recruit both neutrophils and monocytes. Immunobiology 214: 835-842.

Quantock AJ, Young RD (2008) Development of the corneal stroma, and the collagen-proteoglycan associations that help define its structure and function. Dev Dyn 237: 2607-2621.

Rabinowitz YS (1998) Keratoconus. Surv Ophthalmol 42: 297-319.

Radner W, Zehetmayer M, Skorpik C, Mallinger R (1998) Altered organization of collagen in the apex of keratoconus corneas. Opbthalmic Res 30: 327-332

Roberg K, Johansson U, Ollinger K (1999) Lysosomal release of cathepsin D precedes relocation of cytochrome $\mathrm{c}$ and loss of mitochondrial transmembrane potential during apoptosis induced by oxidative stress. Free Radic Biol Med 27: 1228-1237.

Romero-Jiménez M, Santodomingo-Rubido J, Wolffsohn JS (2010) Keratoconus: a review. Cont Lens Anterior Eye 33: 157-166.

Runager K, Basaiawmoit RV, Deva T, Andreasen M, Valnickova Z, Sørensen CS, Karring H, Thøgersen IB, Christiansen G, Underhaug J, Kristensen T, Nielsen NC, Klintworth GK, Otzen DE, Enghild JJ (2011) Human phenotypically distinct TGFBI corneal dystrophies are linked to the stability of the fourth FAS1 domain of TGFBIp. $J$ Biol Chem 286: 4951-4958.

Saghizadeh M, Chwa A, Aoki A, Lin B, Pirouzmanesh A, Brown DJ, Ljubimov AV, Kenney MC (2001) Altered expression of growth factors and cytokines in keratoconus, bullous keratophaty and diabetic human corneas. Exp Eye Res 73: 179-189.

Saijyothi AV, Fowjana J, Madhumathi S, Rajeshwari M, Thennarasu M, Prema P, Angayarkanni N (2012) Tear fluid small molecular antioxidants profiling shows lowered glutathione in keratoconus. Exp Eye Res 103: 41-46.

Sawaguchi S, Twining SS, Yue BY, Chang SH, Zhou X, Loushin G, Sugar J, Feder RS (1994) Alpha 2-macroglobulin levels in normal human and keratoconus corneas. Invest Ophthalmol Vis Sci 35: 40084014.
Sawaguchi S, Twining SS, Yue BY, Wilson PM, Sugar J, Chan SK (1990) Alpha-1 proteinase inhibitor levels in keratoconus. Exp Eye Res 50: 549-554.

Semina EV, Mintz-Hittner HA, Murray JC (2000) Isolation and characterization of a novel human paired-like homeodomain-containing transcription factor gene, VSX1, expressed in ocular tissues. Genomics 63: 289-293.

Sherwin T, Brookes NH (2004) Morphological changes in keratoconus: pathology or pathogenesis. Clin Experiment Ophthalmol 32: 211-217.

Sherwin T, Brookes NH, Loh IP, Poole CA, Clover GM (2002) Cellular incursion into Bowman's membrane in the peripheral cone of the keratoconic cornea. Exp Eye Res 74: 473-482.

Sophos NA, Pappa A, Ziegler TL, Vasiliou V (2001) Aldehyde dehydrogenase gene superfamily: the 2000 update. Chem Biol Interact 132: 323-337.

Srivastava OP, Chandrasekaran D, Pfister RR (2006) Molecular changes in selected epithelial proteins in human keratoconus corneas compared to normal corneas. Mol Vis 12: 1615-1525.

Stabuc-Silih M, Ravnik-Glavac M, Glavac D, Hawlina M, Strazisar M (2009) Polymorphisms in COL $4 A 3$ and COL $4 A 4$ genes associated with keratoconus. Mol Vis 15: 2848-2860.

Stabuc-Silih M, Strazisar M, Ravnik-Glavac M, Hawlina M, Glavac D (2010) Genetics and clinical characteristics of keratoconus. Acta Dermatovenerol Alp Panonica Adriat 19: 3-10.

Udar N, Atilano SR, Brown DJ, Holguin B, Small K, Nesburn AB, Kenney MC (2006) SOD1: a candidate gene for keratoconus. Invest Ophthalmol Vis Sci 47: 3345-3351.

Udar N, Kenney MC, Chalukya M, Anderson T, Morales L, Brown D, Nesburn A, Small K (2004) Keratoconus - no association with the transforming growth factor beta-induced gene in a cohort of American patients. Cornea 2004: 13-17.

Valko M, Rhodes CJ, Moncol J, Izakovic M, Mazur M (2006) Free radicals, metals and antioxidants in oxidative stress-induced cancer. Chem Biol Interact 160: 1-40.

Vaziriani J, Basu S (2013) Keratoconus: current perspectives. Clin Ophthalmol 7: 2019-2030

Viswanathan D, Males J (2012) Prospective longitudinal study of corneal collagen crosslinking in progressive keratoconus. Clin Experiment Ophthalmol 41: 531-536.

Weisiger RA, Fridovich I (1973) Mitochondrial superoxide dismutase: site of synthesis and intramitochondrial localization. Biol Chem 248: 4793-4796.

Wheeler J, Hauser MA, Afshari NA, Allingham RR, Liu Y (2012) The genetics of keratoconus: a review. Reprod Syst Sex Disord (Suppl 6): pii: 001 .

Wilson SE, He YG, Lloyd SA (1992) EGF, EGF receptor, basic FGF, TGF beta-1, and interleukin-1 alpha mRNA in human corneal epithelial cells and stromal fibroblasts. Invest Ophthalmol Vis. Sci 33: 1756-1765.

Wilson SE, He YG, Weng J, Li Q, McDowall AW, Vital M, Chwang EL (1996) Epithelial injury induces keratocyte apoptosis: hypothesized role for the interleukin-1 system in the modulation of corneal tissue organization and wound healing. Exp Eye Res 62: 325-327.

Wise R, Wilson SE, He YG, Weng J (1994) Interleukin-1 alpha induces apoptosis in human corneal stromal fibroblast cells. Invest Ophthalmol Vis Sci 35: 1980.

Wojcik KA, Kaminska A, Blasiak J, Szaflik J, Szaflik JP (2013) Oxidative stress in the pathogenesis of keratoconus and Fuchs endothelial corneal dystrophy. Int J Mol Sci 14: 19294-19308.

Zhao M, Antunes F, Eaton JW, Brunk UT (2003) Lysosomal enzymes promote mitochondrial oxidant production, cytochrome c release and apoptosis. Eur J Biochem 270: 3778-3786.

Zhou L, Sawaguchi S, Twining SS, Sugar J, Feder RS, Yue BY (1998) Expression of degradative enzymes and protease inhibitors in corneas with keratoconus. Invest Ophthalmol Vis Sci 39: 1117-1124. 